\title{
A Case of Acinetobacter lwoffii in an Aborted Calf
}

\author{
Neval Berrin Arserim \\ Department of Microbiology, Faculty of Veterinary Medicine, \\ University of Dicle, 21280, Diyarbakir, Turkey \\ E-mail: nevalb@dicle.edu.tr \\ Nurdan Karacan Sever \\ Department of Microbiology, Faculty of Veterinary Medicine, \\ University of Dicle, 21280, Diyarbakir, Turkey \\ E-mail: nurdankaracan@ hotmail.com.tr \\ Ozkan Unver \\ Department of Pathology, Faculty of Veterinary Medicine, \\ University of Dicle, 21280, Diyarbakir, Turkey \\ E-mail: ounver@dicle.edu.tr \\ Oktay Keskin \\ Department of Microbiology, Faculty of Veterinary Medicine, \\ University of Harran, 63300, Sanliurfa, Turkey \\ E-mail: okeskin@harran.edu.tr \\ Filiz Ozcan (Corresponding author) \\ Department of Fisheries and Diseases, Faculty of Veterinary Medicine, \\ University of Dicle, 21280, Diyarbakir, Turkey \\ E-mail: felizozcan@gmail.com; filiz.ozcan@dicle.edu.tr
}

\begin{abstract}
In the genus that was first isolated from the soil under the name of Micrococcus calcoaceticus in 1911 and called Acinetobacter today, a total of 32 species have been identified, 22 of which have received valid names and the rest are named as "genomic group". Species belonging to the genus Acinetobacter are low-virulence, opportunistic pathogens found in nature, soil and polluted water. They pose a risk because they cause a wide variety of infections in humans and have multiple antibacterial resistance. In many different animal species, mastitis, metritis, abortion, septicemia, chronic hematuria, etc. cases and A. lwoffii were reported from the upper respiratory tract and vaginal flora. The purpose of this case report is to make a report of $A$. lwoffii isolated from an aborted fetus.
\end{abstract}

Keywords: Acinetobacter lwoffii, aborted calf, Acinetobacter sp.

DOI: $10.7176 /$ JSTR/6-13-02

\section{Aborte Bir Buzağıda Acinetobacter lwoffii Olgusu}

Özet

$\mathrm{Bu}$ olgu sunumunda 5 yaşında Holştayn Melezi anneden gebeliğinin sekizinci ayında atılan fötus, Dicle Üniversitesi Veteriner Fakültesi Patoloji Anabilim Dalı'na getirilmiştir. Nekropsi materyallerinden yapılan mikrobiyolojik analiz sonucunda Acinetobacter lwoffii izole ve identifiye edilmiştir. Bu rapor, ineklerde abortusa sebep olan yaygın bakteriyel etkenlerin yanı sira ayırıcı tanıda Acinetobacter türlerinin de göz önünde bulundurulması gerektiğini düşündürmüştür.

Anahtar Kelimeler: Acinetobacter lwoffii, aborte buzağı, Acinetobacter sp.

12 | P a g e

www.iiste.org 


\section{Giriş}

Acinetobacter spp. ilk kez 1911'de Beijerinck tarafindan Micrococcus calcoaceticus adiyla topraktan izole edildi. Bu etken, fizyolojik karakterlerindeki farklılıkların ayrımındaki zorluklar sebebiyle uzun y1llar boyunca birçok farklı tür ve cins adlarıla (Achromobacter, Alcaligens, Mima, Neisseria Achromobacter anitratus, Diplococcus mucosus, Mimapolymorpha, M. calcoaceticus, Moraxella lwoffii, Neisseria winogradskyi vb.) tanımlandı [1, 9, 12, 21]. Y1llar içinde gelişen ve değişen moleküler teknikler sayesinde şu ana kadar Acinetobacter cinsine ait 22'si geçerli isim almış, geri kalanları ise 'genomik grup' olarak adlandırılmış toplam 32 tür tanımlanmıştır $[9,10,11] \mathrm{Bu}$ türler arasında $A$. baumannii klinik enfeksiyonlarla ilişkilendirilen ana türdür. A. baumannii' yi, $A$. haemolyticus, A. junii, A. Johnsonii ve A. lwofii takip etmektedir [5, 9]. Acinetobacter cinsine ait türler doğada, toprakta, kirli sularda bulunan düşük virulensli, firsatçı patojenlerdir [8, 19, 22]. Ancak günümüzde karbapenem ve geniş spektrumlu laktamazlar da dahil olmak üzere birçok antibiyotik direnç mekanizmasına sahip oldukları bilinmektedir. Bugün Acinetobacter türlerinin insanlarda sebep olduğu enfeksiyonların ve bulaşma yollarının çeşitliliği (santral venöz ve üriner kateterizasyon, mekanik ventilasyon, sebze, et ve et ürünleri, süt ve süt ürünleri tüketimi vb.) ile çoklu antibakteriyel dirence sahip olmaları halk sağlığını ciddi düzeyde tehdit etmektedir [21, 22].Birçok farklı hayvan türünde mastitis, metritis, abortus, septisemi, kronik hematüri vb. vakalar ile üst solunum yolu ile vajinal floradadan A. lwoffii (eski adiyla Mima polymorpha, Acinetobacter calcoaceticus var. lwoffii)

[4] bildirimi yapılmıştır $[13,14,15,16,17,20] \mathrm{Bu}$ olgu sunumunun amacı lwoffii'nin bildirimini yapmaktır.

\section{Olgu}

Hastalık materyali olarak 5 yaşında Holştayn Melezi anneden gebeliğinin sekizinci ayında atılan fötus, Dicle Üniversitesi Veteriner Fakültesi Patoloji Anabilim Dalı'na getirilmiştir. Hayvan sahibinden alınan anamnezde, hayvan sahibinin 20 tane gebe hayvanı olduğu ve bunların dokuz tanesinin abort yaptığı öğrenildi. Yetiştiricinin doğal aşım için aynı boğayı kullandığı ve çevre yetiştiricilerde herhangi bir atık olayının olmadığı ve besi için Siverek’ten aldığı sığırları da gebe hayvanların yanına getirdiği, aynı ahırı ve bahçeyi kullandığı öğrenildi. Herhangi bir makroskopik lezyon bulunmayan aborte fötustan dan alınan abomasum içeriği, karaciğer ve akciğer doku örnekleri Kanlı agar, MacConkey Agar ve Brucella Agar(Farrel) besiyerine ekimler yapıldıktan sonra aerobik ve mikroaerobik koşullarda $37^{\circ} \mathrm{C}^{\prime}$ de inkübasyona kaldırıldı. 24 saatlik inkübasyon süresi sonunda Kanlı agarda ve MacConkey agarda üreme görüldü. Kolonilerden yapılan Gram boyamada Gram (-) çomaklar görüldü. Kanlı Agardaki şeffaf beyaz kolonilerden alınan örneklerden bakteriyel identifikasyon, Dicle Üniversitesi Veteriner Fakültesi Besin Hijyeni ve Gida Teknolojisi Anabilim Dalı'nda bulunan VITEK 2.(Biomerieux) cihazı ile yapıldı. Etken, Acinetobacter lwoffii olarak identifiye edildi. (Tablo.1)

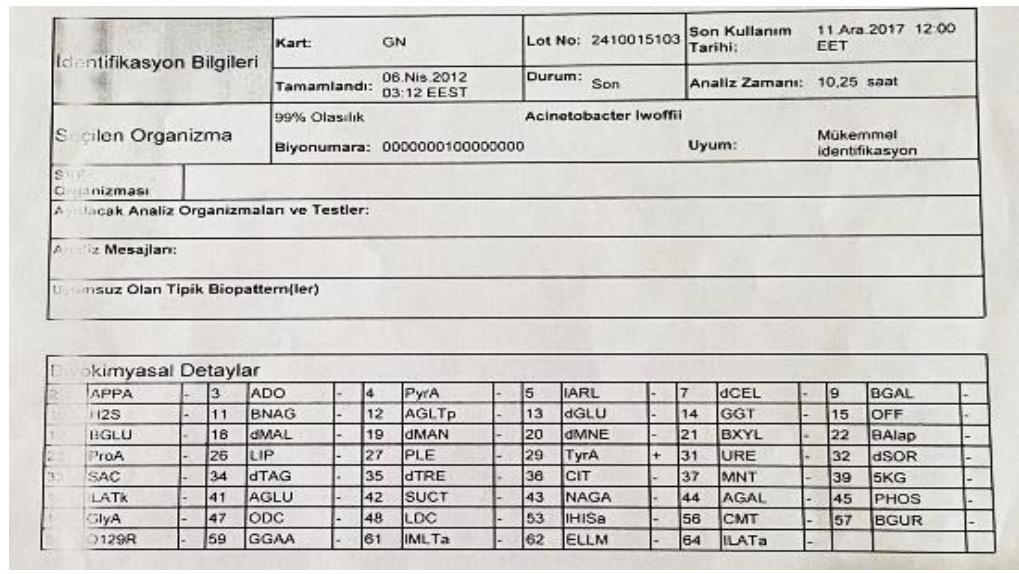

Tablo 1. Vitek Sonucu

\section{Tartışma ve Sonuç}

Acinetobacter türleri, doğada yaygın olarak bulunan firsatçı virulensi düşük patojenlerdir. Ancak son y1llarda immun sistemi baskılanmış, hastanelerde yatarak tedavi gören hastalarda önemli seviyede çeşitli enfeksiyonlara sebep olmaktadır. Çoklu antibiyotik direnci kazanmasıyla birlikte hastaların tedavisinde büyük sıkıntılar yaşanan patojen bir tür haline gelmiştir [8,9,12,21] A.lwoffii' nin 
hayvanların yaşadığı çevrede yaygın olarak bulunduğu, immun sistemi baskılanmış hayvanlarda çeşitli sporadik enfeksiyonlara neden olduğu bildirilmiştir[6,7,8] Acinetobacter türlerinin doğada ve vajinal mukozada bulunmasının yanı sıra antibiyotik dirençli A. calcoaceticus suşlarının kontamine boğa sperması ile invitro fertilizasyon sistemine dahil olduğu da bilinmektedir [2,3] $\mathrm{Bu}$ rapor, ineklerde abortusa sebep olan yaygın bakteriyel etkenlerin yanı sıra Acinetobacter türlerinin de göz önünde bulundurulabileceğini düşündürmüştür.

\section{Referanslar}

[1] Almasaudi, S.B. (2018) Acinetobacter spp. as nosocomial pathogens: Epidemiology and resistance features. Saudi journal of biological sciences, 25(3): 586-596. DOI: 10.1016/j.sjbs.2016.02.009

[2] Arora, AK., Gupta, SC., Kaushik , RK. (1986) Detection of upper respiratory tract bacterial carriers in poultry Indian Veterinary Medical Journal, 10(2), 63-67, 1986

[3] Bielanski, A. (2007) Disinfection procedures for controlling microorganisms in the semen and embryos of humans and farm animals. Theriogenology, 68(1), 1-22 DOI: 10.1016/ j.theriogenology.2007.03.025

[4]Bouvet, PJM., Jeanjean, S. (1989). Delineation of new proteolytic genomic species in the genus Acinetobacter. Research in microbiology, 140(4), 291-299 DOI: 10.1016/0923-2508(89)900211.

[5]Cai, H., Archambault, M., Prescott, JF (2003)16S ribosomal RNA sequence-based identification of veterinary clinical bacteria. Journal of veterinary diagnostic investigation, 15(5), 465-469 DOI: 10.1177/104063870301500511

[6] Das, AM., Paranjape, VL (1986) Acinetobacter calcoaceticus in three cases of late abortion in water buffaloes. Veterinary Rec, 118(8), 214-214, 1986. DOI: 10.1136/vr.118.8.214

[7]Diker. KS., Arda, M., İzgür, H (1986) .Isolation of Acinetobacter calcoaceticus from cows with metritis. J. Vet. Med, 33: 632-633, 1986. DOI: 10.1111/j.1439-0450.1986.tb00079.x

[8] Diker, KS. (2006) Moraxella ve Acinetobacter İnfeksiyonları. In, Aydın N., Paracıkoğlu J (Ed): Veteriner Mikrobiyoloji (Bakteriyel Hastalıklar). 223-227, İlke Emek Yayınları, Ders Kitabı, Ankara.

[9] Doughari, HJ., Ndakidemi, PA., Human, IS., Benade, S. (2011) The ecology, biology and pathogenesis of Acinetobacter spp.: an overview. Microbes and environments, 26(2), 101-112, 2011. DOI: $10.1264 /$ jsme2.ME10179

[10]Erganiş, O., Çorlu, M., Kaya, O., Ateş, M (1988) Isolation of Acinetobacter calcoaceticus from septicaemic hens. Vet. Rec, 123: 374, 1988. DOI: 10.1111/j.1439-0450.1986.tb00079.x

[11] Gottschalk, G., Pasin1, MI., Ilanos, GA. (1984). Acinetobacter Iwoffi y Moraxella sp. Enyeguas con problemas reproductives. Vet. Argentina, 1: 488-492 DOI: 10.1111/j.1439-0450. 1986.tb00079.x

[12] Hanlon, GW. (2005) The emergence of multidrug resistant Acinetobacter species: a major concern in the hospital setting. Letters in applied microbiology, 41(5), 375-378, 2005. DOI: 10.1111/j.1472-765X.2005.01791.x

[13]Husted, JR. (2005)Bacterial and fungal organisms in the vagina of normal cows and cows with vaginitis (Doctoral dissertation, Texas A\&M University 
[14]Kaya, O., Ateş, M., Erganiş, O., Çorlu M., Şanlıŏlu, S. (1989) Isolation of Acinetobacter Iwoffi from hens with septicemia. J. Vet. Med, 36: 157-158, DOI: 10.1111/j.14390450.1989.tb00584.x

[15]Poirel, L., Berçot, B., Millemann, Y., Bonnin, RA., Pannaux G., Nordmann, P. (2012). Carbapenemase-producing Acinetobacter spp. in cattle, France. Emerging infectious diseases, 18(3), 523 DOI: 10.3201/eid1803.111330

[16] Rahman, H., Baxı, KK (1985) Isolation of Acinetobacter calcoaceticus from a cow with mastitis. Zbl. Vet. Med, 32: 71-72, 1985. DOI: 10.1111/j.1439-0450.1985.tb01939.x

[17]Rajasekhar, M., Muniyappa, L., Murthy, BS. (1978) Chronic haematuria caused by Acinetobacter calcoaceticus in a race horse. Vet Rec, 102(25):557.

[18] Raka L., Mulliqi-Osmani G., Begolli L., Kurti A., Lila G., Bajrami R., Jaka-Loxha A (2013) Acinetobacter. In, Basak S (Ed): Infection Control. 83-92, Intech.

[19]Towner, KJ. (2009) Acinetobacter: an old friend, but a new enemy. Journal of Hospital Infection, 73(4), 355-363 DOI: 10.1016/j.jhin.2009.03.032

[20]Wani, SA., Samanta, I., Bandey, MT., Bhat, MA. (2006) Isolation of Acinetobacter Iwoffii from broiler chicken with septicaemia in Kashmir valley. Indian Journal of Animal Research, 40(1), 61-63,

[21] Wong,D., Nielsen, TB., Bonomo, RA., Pantapalangkoor, P., Luna, B., Spellberg B (2017) Clinical and pathophysiological overview of Acinetobacter infections: a century of challenges. Clinical microbiology reviews, 30(1), 409-447 DOI: 10.1128/CMR.00058-16

[22] Vaneechoutte, M., Dijkshoorn L., Nemec A., Kämpfer, P., Wauters (2011 )Acinetobacter, Chryseobacterium, Moraxella, and other nonfermentative Gram-negative rods. In Versalovic J, Carroll KC, Funke G, Jorgensen JH, Landry ML, David W, Warnock DW (Ed): Manual of Clinical Microbiology, $10^{\text {th }}$ ed., 714-738, American Society of Microbiology. 